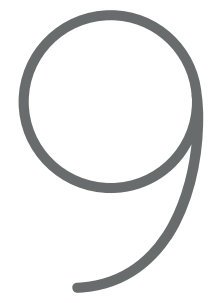

\title{
HERNÁN MALO \\ Y LA UNIVERSIDAD ECUATORIANA
}

Estuardo Arellano E. 
Una vez más se cumple aquello de que es menester que una persona muera para que podamos cobrar las verdaderas dimensiones de su personalidad.

Efectivamente, nos hemos congregado para esbozar algunos de los méritos de Hernán Malo González, entrañable amigo y connotado humanista y pensador, que hace poco se alejó de nosotros definitivamente.

Más tarde y con mayores luces admiraremos su personalidad; por ahora voy a limitarme a considerar sus méritos de educador.

El aporte que hiciera Hernán Malo González a la educación superior, puede observarse en tres circunstancias de su vida: en primer lugar, durante el ejercicio de las funciones de Rector de la Universidad Católica de Quito; en segundo lugar, en sus relaciones con las universidades estatales y, finalmente en su producción escrita.

\section{I}

Desde 1971 hasta 1978 ejerció las funciones de Rector de la Universidad Católica de Quito, después de haber dictado en ella las cátedras de Ética, Filosofía Griega y Antropología Cultural y de haber sido Decano de la Facultad de Filosofía.

Su rectorado constituye un hito en la historia de las universidades católicas ecuatorianas, ya que su pronunciamiento de "ecuatorianizar la universidad" imprime un nuevo rumbo a estas instituciones educativas. Ecuatorianizar la universidad significa, para Hernán Malo, emprender, desde la universidad, la tarea de rescate de la identidad nacional y poner la universidad al servicio de la sociedad ecuatoriana; lo que implica una nueva concepción de la universidad y una nueva filosofía de la educación.

"Nos hallamos en una auténtica tarea de rescate de nuestro pensamiento. Con este espíritu irrumpimos en el pretérito desde nuestra actualidad y para nuestra actualidad", dice en el Prólogo al libro Pensamiento Universitario Ecuatoriano; y allí mismo afirma que el móvil de la Biblioteca Básica Ecuatoriana es "la íntima convicción y necesidad de escrutar lo que fuimos y pensamos, para dar coherencia a nuestro ser y pensar actual y a sus cauces futuros" (Pág. 15). 
Para cumplir estos propósitos, desde la universidad, funda Hernán Malo el Departamento de Historia y Geografía en la Facultad de Ciencias de la Educación y reorganiza la Facultad de Ciencias Humanas, dotándola del Departamento de Antropología y el de Ciencias Sociales y Políticas, a más de la Facultad de Filosofía que ya se encontraba funcionando.

Poner la universidad al servicio de la sociedad ecuatoriana significa asignarle la tarea de responder, ante todo, a las necesidades del desarrollo nacional; con lo cual se está tocando temas tan delicados como las relaciones Universidad y Sociedad, Universidad y Estado. Efectivamente, la Universidad, inmersa y todo en la sociedad, se diferencia de ella por sus fines específicos: así, si la sociedad civil tiene por finalidad implantar la democracia en el país, no es éste el objetivo específico de la universidad, la cual, sin entrar en contradicción con los afanes democráticos de la sociedad, ha de preocuparse por satisfacer las necesidades del desarrollo nacional, desde el ámbito de la preparación profesional, capacitación técnica y desenvolvimiento científico. Por otro lado, siendo el Estado responsable del desarrollo nacional, ha de elaborar los planes de desarrollo y consecuentemente ejercitar políticas de fomento a la producción económica, de servicio y seguridad sociales, de educación, etc.; en lo cual la universidad encuentra un amplísimo campo para desarrollar las profesiones, la ciencia y la técnica, aplicándolas a la concreta realidad del país; no siendo esta colaboración, en modo alguno, sometimiento o sujeción, pues seguirá en pie el espíritu crítico, en cumplimiento de la autonomía institucional.

De esta manera se esboza la imagen de una universidad humanística y técnica, a la vez que integral; consagrada a satisfacer la demanda nacional de profesionales, técnicos, científicos y conductores sociales, de acuerdo a las exigencias de la transformación del país. Es este esbozo el que trata de hacer realidad Hernán Malo en la Universidad Católica de Quito.

¡Cuán lejos estamos de la universidad al servicio de la fe cristiana o de la Iglesia Católica! Y no es que el entonces Rector de la Universidad Católica renunciara. a la vivencia comunitaria de su fe religiosa o a la visión cristiana de la sociedad y sus instituciones; sino que, apurando la distinción entre fe y ciencia y en salvaguarda de la autonomía de ésta frente a aquella, encontró válido el poner a las instituciones temporales, como la universidad, al servicio del hombre societario, según el feliz pensamiento de Teilhard de Chardin, para quien la misión del cristiano consiste en humanizar al mundo y sus instituciones. 
Estos los alcances del propósito de ecuatorianizar la universidad católica.

¡No faltaron ante estas perspectivas las críticas miopes de los mediocres que no entienden, ni los dardos hostiles de los sectarios que jamás tuvieron hermanos!

\section{II}

Mérito es de Hernán Malo el haber concebido a las 17 instituciones universitarias existentes dentro de la concepción unitaria de la patria. Esta concepción de la Universidad Ecuatoriana, una en sus objetivos y metas para servicio de la sociedad y diversa en su realización histórica, implícitamente más que explícitamente preside la redacción del Estudio Introductorio al Libro Pensamiento Universitario Ecuatoriano. A modo de prueba citemos solamente dos párrafos:

Conviene advertir, nos dice, que la historia de la universidad ecuatoriana es hasta 1868 la historia de la Universidad de Quito, la Única que hasta entonces existió. A partir de esa fecha entran en la vida nacional las universidades de Guayaquil y Cuenca. Tengamos en cuenta que la Universidad nacional de Loja se funda con rigor de la ley en la presidencia de Carlos Arroyo del Río. A partir de 1946, con la creación de la Universidad Católica del Ecuador, comienza el crecimiento o más bien dicho la multiplicación de tales instituciones..... después de la aparición de nuevas universidades, la Universidad Central del Ecuador mantiene un papel no sólo de conducción del pensar y obrar universitarios, sino constituye algo así como la cifra y el signo de la problemática y de los avatares universitarios del Ecuador (Págs. 29-30).

Y más abajo añade:

A partir de la edad moderna la universidad no sólo es centro ele la razón sino de las razones. Ello alude a las grandes escuelas filosóficas (y luego sociales) que en una $u$ otra forma prosperaron, se debatieron, se sintetizaron en 
las universidades. La universidad se convierte en la gran intérprete del mundo y del hombre a la luz de la inteligencia; es la buscadora de las explicaciones radicales (en el rico sentido etimológico de ir a la ra(z); todo ello en un clima de autonomía del pensar. Y esto ha seguido así, pese a ofuscaciones o ataduras esporádicas provenientes de imposiciones políticas o de extremismos religiosos (Págs. 44-45).

Nutrido en estos conceptos es como Hernán Malo inicia el diálogo con las universidades estatales, superando definitivamente la barrera entre educación católica y educación laica.

Si bien no tuvo la oportunidad de llevar esta actitud a concreciones de mayor alcance, ella habla bien a las claras de la clarividencia y justeza de sus apreciaciones, así como de su espíritu ecuménico y sólidamente democrático.

\section{III}

Aún no hemos podido hacer la recopilación completa de los escritos de Hernán Malo acerca de la universidad: discursos, conferencias, ponencias en reuniones o simposios de carácter científico, artículos para revistas y estudios para publicarse en algunos libros.

Merece especial consideración el estudio del Plan Maestro de la Universidad Católica; su ponencia en el Encuentro de Filosofía sobre la Crisis de la Razón que lleva el título de Universidad Sede de la Razón y el "Estudio Introductorio" al libro Pensamiento Universitario Ecuatoriano, que es el tomo XIV de la Biblioteca Básica del Pensamiento Ecuatoriano. Sabemos que, sobre este tema, quedaron sobre su escritorio algunas páginas tal vez inconclusas.

En su escrito Universidad Sede de la Razón, son magistrales las páginas que consagra a desentrañar los temas acerca de la vinculación histórica de la Universidad con la razón y de las condiciones del compromiso intrínseco de la Universidad con la razón. En el "Estudio Introductorio" al Pensamiento Universitario Ecuatoriano, hay que destacar la acuciosidad con que traza el Panorama Histórico de la Universidad Ecuatoriana, hasta descubrir el Concepto de Universidad dentro del Dinamismo Histórico, en la contraposición de Dos Visiones de 
la Universidad: la de Benigno Malo y la de García Moreno y dos concepciones de educación: la liberal laica y la confesional católica. Y ahí se quedó inconcluso su estudio, porque le sobrevino la muerte.....

De todos modos, no es hora aún de intentar la recopilación de su pensamiento universitario; dejemos iniciado el asunto con el mismo recato con el que él lo hizo.

Para terminar, digamos que nunca los méritos de una persona podrán ser valorados como se merecen, porque, al hacerlos, se consumó una vida que es única y sin repetición.

Digamos que Hernán Malo agotó su existencia en méritos que, sin exageración, enaltecen la estirpe cuencana y la genialidad ecuatoriana: menudo en su cuerpo, grande en su espíritu e inmenso en su corazón, quedará para la posterioridad como un ilustre humanista contemporáneo y un gran pensador ecuatoriano. recordarlo.

Como ya se ha dicho: si duele el perderlo, consuela el 
